\title{
Legal needs of patients attending an urban family practice in Hamilton, Ontario, Canada: an observational study of a legal health clinic
}

Gina Agarwal ${ }^{1,2^{*}}$ D, Melissa Pirrie ${ }^{1}$, Dan Edwards ${ }^{3}$, Bethany Delleman ${ }^{1}$, Sharon Crowe ${ }^{4}$, Hugh Tye $^{4}$ and Jayne Mallin ${ }^{5}$

\begin{abstract}
Background: Individuals living in poverty often visit their primary care physician for health problems resulting from unmet legal needs. Providing legal services for those in need may therefore improve health outcomes. Poverty is a social determinant of health. Impoverished areas tend to have poor health outcomes, with higher rates of mental illness, chronic disease, and comorbidity. This study reports on a medical-legal collaboration delivered in a healthcare setting between health professionals and lawyers as a novel way to approach the inaccessibility of legal services for those in need.
\end{abstract}

Methods: In this observational study, patients aged 18 or older were either approached or referred to complete a screening tool to identify areas of concern. Patients deemed to have a legal problem were offered an appointment at the Legal Health Clinic, where lawyers provided legal advice, referrals, and services for patients of the physicians. Fisher's exact test was used to compare populations. Binary logistic regression was used to determine the factors predicting booking an appointment with the clinic.

Results: Eighty-four percent $(n=648)$ of the 770 patients screened had unmet legal needs and could benefit from the intervention, with an average of $3.44(S D=3.42)$ legal needs per patient screened. Patients with legal needs had significantly higher odds of attending the Legal Health Clinic if they were an ethnicity that was not white (OR= 2.48; 95\% Cl 1.14-5.39), did not have Canadian citizenship ( $\mathrm{OR}=4.40 ; 95 \% \mathrm{Cl} 1.48-13.07)$, had housing insecurity $(\mathrm{OR}=3.33 ; 95 \% \mathrm{Cl} 1.53-7.24)$, and had difficulty performing their usual activities ( $\mathrm{OR}=2.83 ; 95 \% \mathrm{Cl} 1.08-7.43)$. As a result of the clinic consultations, 58.0\% $(n=40)$ were referred to either Legal Aid Ontario or Hamilton Community Legal Clinic, $21.74 \%(n=15)$ were referred to a private lawyer; one case was taken on by the clinic lawyer.

\footnotetext{
* Correspondence: gina.agarwal@gmail.com

'Department of Family Medicine, McMaster University, Hamilton, Canada

${ }^{2}$ Department of Health Research Methods, Evidence, and Impact, Hamilton,

Canada

Full list of author information is available at the end of the article
}

(c) The Author(s). 2020 Open Access This article is licensed under a Creative Commons Attribution 4.0 International License, which permits use, sharing, adaptation, distribution and reproduction in any medium or format, as long as you give appropriate credit to the original author(s) and the source, provide a link to the Creative Commons licence, and indicate if changes were made. The images or other third party material in this article are included in the article's Creative Commons licence, unless indicated otherwise in a credit line to the material. If material is not included in the article's Creative Commons licence and your intended use is not permitted by statutory regulation or exceeds the permitted use, you will need to obtain permission directly from the copyright holder. To view a copy of this licence, visit http://creativecommons.org/licenses/by/4.0/ The Creative Commons Public Domain Dedication waiver (http://creativecommons.org/publicdomain/zero/1.0/) applies to the data made available in this article, unless otherwise stated in a credit line to the data. 
(Continued from previous page)

Conclusion: The Legal Health Clinic was found to fulfill unmet legal needs which were abundant in this urban family practice. This has important implications for the future health of patients and clinical practice. Utilizing a Legal Health Clinic could translate into improved health outcomes for patients by helping overcome barriers in accessing legal services and addressing social causes of adverse health outcomes.

Keywords: Primary care, Medical-legal partnership, Legal needs, Social determinants of health, System navigation, Poverty

\section{Background}

Patients living in poverty often consult with their family physicians for assistance with health problems that are the result of unidentified and unmet legal needs [1]. Data from the USA and Canada suggests that people of low income may have two or three unmet legal needs [2-4]. Though family physicians may know about this association between poverty, legal issues, and health, they are unable to help their patients with their legal issues due to a lack of legal knowledge, time and resources [5]. The inaccessibility of legal services to low income individuals could be considered a social determinant of health $[6,7]$. In contrast, providing access to justice for those in need may improve poverty and therefore health outcomes [4, 7]. Possible legal mechanisms for reducing poverty include: appeasing debtors, accessing available benefit programs, preventing eviction from housing, addressing unsafe housing conditions, seeking court action to gain spousal support, and settling other court actions $[2,6]$. Breaking the cycle of poverty requires dedicated professionals working together as a team to give the patient/client opportunities and support [7]. Therefore, the healthcare setting is an ideal situation for this type of inter-professional collaboration to occur [7].

In 2016 , $13 \%$ or 4.5 million Canadians were living in poverty [8] based on the Low Income Measure (LIM) [9]. Poverty is widely recognized as a social determinant of health $[10,11]$. The World Health Organization describes social determinants of health as "the conditions in which people are born, grow, live, work and age," factors that are heavily influenced by wealth distribution, power and resources [11, 12]. Due to this direct link between poverty and health, it is not surprising that poverty is a serious problem identified in primary care, especially in low socioeconomic status (SES) communities [5]. For example, insufficient income can result in lack of access to medicines and untreated or sub-optimally treated chronic illness [13, 14]. Poor diet and stressful environments can lead to poor lifestyle choices and, as a result, mental illness, chronic disease and multiple co-morbidities that affect overall quality of life $[13,14]$.

Medical-legal collaborations delivered in a healthcare setting between health professionals and lawyers can present a novel way to approach these types of problems, by addressing the legal needs that influence poverty $[15,16]$. These partnerships can reduce stress and improve the wellbeing of clients through increased access to resources and better awareness of social services as shown in limited evidence from the USA $[1,17]$. Medical-legal partnerships of differing varieties have been adopted in more than three hundred health care delivery situations in the USA, [18] though first developed at Boston Medical Center in 1993 [7]. In 2006 a National Centre for Medical-Legal Partnership was created; legal-aid agencies, pro-bono lawyers, and law schools partner with hospitals and health clinics, offering assistance with patients' unmet legal needs in health care settings [7]. However, medical-legal partnerships are a new concept in Canada and while some collaborations already exist in pediatric hospitals, [2] they have not been rigorously evaluated in a primary care setting. Thus, it is necessary to develop, implement and evaluate such partnerships to inform future medical-legal partnerships in Canada.

With $15 \%$ of residents below the LIM definition of poverty [19] and a high rate of emergency shelter use, [20] Hamilton, Ontario is an area of low SES. Hamiltonians' health is affected by poverty such that there is a significant disparity in life expectancy, with individuals in poor areas expected to live 21 years fewer than those living in wealthier areas [21]. Chronic disease rates are slightly higher than those in Canada as a whole, and lifestyle behaviors are slightly worse [22]. Hamilton is therefore an optimal urban location for the implementation and evaluation of a medical-legal partnership.

This paper reports the development of a novel legal assessment clinic embedded within primary care and explores the following research questions:

1) What are the types of legal needs identified when screening in a primary care setting?

2) What are the characteristics of the population with legal needs in primary care and are they significantly different from those without legal needs in the same setting?

3) What characteristics are associated with individuals choosing to access the legal health clinic?

\section{Methods}

\section{Research design}

A Legal Health Clinic (LHC) in an urban primary care setting was developed and implemented. A cross- 
sectional observational design was used to evaluate the amount of legal need in primary care, the characteristics of those with legal needs and of LHC attendees. Ethical clearance was granted by the Hamilton Integrated Research Ethics Board.

\section{Participants and setting}

Patients aged 18 years or over were either approached in the family practice waiting room by a research assistant to complete a screening tool (Legal Health Check-Up survey) [1] or were referred to the LHC by their primary care doctor or other healthcare staff within the clinic, and then completed the screening tool. For patients not screened in the waiting room, referral criteria utilised by the family doctor or other healthcare staff were that the patient needed to have a potential legal need such as an upcoming eviction, that had been discussed with the healthcare provider and was concerning for their health outcomes. These patients would then need to complete the screening tool. There were no exclusion criteria, however participants needed to bring their own translators if they did not speak English.

The study was set in a primary care medical clinic within a family health team (FHT) with approximately 13,000 patients, in Hamilton, Ontario.

\section{Development of the legal health clinic}

This study involved providing legal aid services, in the form of a weekly clinic for patients of the FHT's physicians. The legal clinic was created through a three-way partnership: between the FHT, Hamilton Community Legal Clinic (HCLC) and Legal Aid Ontario (LAO). A lawyer from each legal partner was onsite in the FHT clinical space, every week, on an alternating basis. The lawyers provided legal advice on multiple domains of law. The HCLC lawyer had expertise with housing, employment, social assistance, and human rights issues while the LAO lawyer had expertise on criminal, family, refugee, and estate law. As a result, the McMaster Family Practice LHC became available as a free service to patients of the FHT during this study, with the intention to continue afterwards if it was deemed feasible.

\section{Data collection}

The Legal Health Check-Up survey [23] was used as a screening tool to identify areas of possible concern and to initiate a conversation with participants about legal problem areas. It contained questions about stability of income and housing, benefit status, existence of a will, pending legal worries and discrimination or human rights issues, to name a few. Legal needs were those housing, financial, employment, social assistance, immigration, benefit needs, and other concerns that involved legal processes that either the patient did not have access to or did not understand. In collaboration with LAO, HCLC, and the FHT's system navigator, an algorithm was developed to determine if the concern identified was a legal issue or if it was a non-legal issue that could be better addressed by the system navigator. Participants identified to have a legal issue were offered an appointment with the LHC, but could also elect to handle the problem on their own, with or without the help of the system navigator. Participants wanting to pursue legal help were matched to a lawyer in the LHC with experience in the appropriate legal domain (e.g. housing).

In conjunction with the Legal Health Check-Up survey, participants also completed a study survey asking their demographics (age, gender, marital status, educational status, income level, citizenship status and ethnicity), quality of life (EQ-5D-3L), [24] self-reported health status, [25] benefit status and poverty indicators not already captured in the Legal Health Check-Up survey. The three added poverty indicator questions have been validated for use in healthcare settings $[26,27]$ and measured income security ("Do you have difficulty making ends meet at the end of the month?"), [26] housing security ("Do you ever worry about losing your place to live?"), [26] and food security ("In the past month, was there any day when you or anyone in your family went hungry because you did not have enough money for food?") [26, 27].

The LIM 50 is a common poverty threshold used internationally [9]. The indicator determines if the individual's household income is below the median household income in their country, adjusted for their household size [9]. Since household size was not included in the baseline surveying, LIM 50 could not be calculated for the full sample. However, individuals who opted to complete the follow-up survey (open to all baseline participants) provided household size, which allowed LIM 50 to be calculated for those individuals. Aside from household size, data collected through follow-up surveying is not presented in this paper.

\section{Intervention: legal health clinic}

At the LHC appointment, participants were scheduled for a 30-min consultation with one of the two lawyers. There were several possible outcomes. Some participants would be provided with resources or educated about an area of law and that would be sufficient to either solve or help with their legal problem. Participants who needed more assistance would be referred to one of four options: 1) LAO, if their income was low enough to qualify for Legal Aid services [28]; 2) HCLC, if their income was low enough to qualify for HCLC services; 3 ) the LHC lawyer, if they opted to take on the case; or, 4) a private lawyer, for those financially ineligible for LAO or HCLC services due to higher income. It was then up 
to the participant to pursue the help recommended to them by the LHC. Participants were able to return to the LHC if they wanted more advice or had a new legal problem.

Information on the Legal Health Check-up survey was uploaded to the participants' medical charts automatically. If the participant provided written consent, information from their legal appointment was added to their electronic medical record, visible to their family physician. The study research assistant scanned the paper documentation and uploaded it to the participant's electronic medical record. Lawyers were not given access to the participant's medical record. If the participant agreed, the legal team communicated with the medical team to arrange necessary items such as physical examinations for the Workers Insurance Safety Board. The lawyers would also recommend that the participant visit other services within the FHT, such as the system navigator, where appropriate.

\section{Data analysis}

Measures were assessed using descriptive analysis, including the number of screening surveys completed, number of LHC appointments and subsequent referrals, and types of legal issues identified. Rates and frequencies of demographic characteristics of those who completed the LHC screening survey, of those with unmet legal needs, of those who made an appointment for the LHC and of those who kept their appointment with the LHC were calculated. Where appropriate chi-squared or Fisher's Exact tests were used to compare populations. Binary logistic regression was completed to determine the factors predicting booking an appointment with the LHC. All statistical tests were performed on SPSS versions 20 and 24.

\section{Results}

In the first 6 months of the program, between April 25, 2016 and October 24, 2016, 770 patients from the FHT consented to participate in the study and completed the Legal Health Check-Up survey. Almost all participants were recruited while waiting as patients in the clinic waiting room $(98.4 \%, n=758)$ and the remaining participants were patients referred directly to the LHC by another source $(1.6 \%, n=12)$. Of the 12 participants referred directly to the LHC, five were referred by their physician within the FHT, five by the FHT system navigator, and two by other patients.

\section{Survey participant demographics}

The demographic characteristics of all participants who completed the study survey $(N=770)$, of those who had at least one legal need $(n=648,84.2 \%)$, and of those who had no legal need $(n=122,15.8 \%)$ are summarized in Table 1. The majority of survey respondents were female (65.6\%), had post-secondary education (59.4\%), owned their residence (51.0\%), were Canadian citizens $(92.8 \%)$, were white $(82.1 \%)$, and did not report receiving financial benefits (e.g. ODSP; 55.5\%). Respondents were most commonly employed full-time (39.4\%) and had a monthly income above $\$ 3000$ (44.3\%). The 18-24 year old age category had the lowest representation (8.4\%) and the 35-44 year old age category had the highest representation (22.5\%).

When comparing those who had a legal need to those who did not, using Fisher's Exact tests, all demographic variables showed a significant difference $(p<0.05)$, except for gender $(p=0.188)$ (see Table 1$)$. Those who had a legal need were predominantly younger, had attained lower education, had lower monthly income, did not own their residence, were not married, did not have Canadian citizenship, and were not white. Of note, the rate of full-time employment was similar between those with and without a legal need (38.9\% versus $42.2 \%$ ), however those without a legal need had a higher rate of retirees (41.4\% versus $11.6 \%)$ while those with a legal need had a higher rate of part-time employment, unemployment, and inability to work (49.5\% versus $16.3 \%)$. Similarly, those who did not have a legal need had a higher rate of receiving Canada Pension Plan (CPP) retirement benefits $(23.8 \%$ versus $7.1 \%)$, while those with a legal need had higher rates of receiving disability, employment, and other benefits (38.6\% versus $14.8 \%$ ).

\section{Poverty indicators, self-reported health status, and quality of life}

The 770 participants who completed the study survey predominantly screened negative for each poverty indicator; $38.1 \%(n=293)$ had income insecurity, $21.9 \%(n=$ $169)$ could not afford their medication, $12.2 \%(n=89)$ could not afford food, and 11\% $(n=80)$ had housing insecurity (see Table 2). In the subset of 283 participants who had household size available from a follow-up survey, 52.7\% $(n=149)$ had a household income below LIM-50, indicating that their household income fell into the poverty bracket. Self-reported Health Status for the full survey sample was Very Good or Excellent in 40.4\% $(n=298)$ of respondents. The EQ-5D-3L tool measuring five domains of quality of life showed that 28.5\% ( $n=$ 208) had mobility issues, $8.0 \%(n=58)$ had difficulties with self-care, $34.7 \%(n=253)$ had issues performing usual activities, $60.6 \%(n=443)$ had issues with pain or discomfort, and $51.9 \%(n=376)$ had some or severe anxiety or depression.

When comparing those who had a legal need to those who did not, using Fisher's Exact tests, all poverty, health status, and quality of life variables showed a significant difference $(p<0.05)$, except for pain and discomfort $(p=$ 
Table 1 Socio-demographic characteristics of participants with and without legal needs and comparisons between these two groups

\begin{tabular}{|c|c|c|c|c|}
\hline & $\begin{array}{l}\text { All survey respondents } \\
N=770 \\
\mathrm{n}(\%)\end{array}$ & $\begin{array}{l}\text { At least one legal need }{ }^{1} \\
n=648 \\
n(\%)\end{array}$ & $\begin{array}{l}\text { No legal needs } \\
n=122 \\
n(\%)\end{array}$ & $\begin{array}{l}\text { Has legal need versus } \\
\text { No legal needs } \\
p \text { value }^{2}\end{array}$ \\
\hline \multicolumn{5}{|l|}{ Age } \\
\hline $18-24$ & $64(8.4)$ & $63(9.8)$ & $1(0.8)$ & \multirow[t]{7}{*}{$p<0.001$} \\
\hline $25-34$ & $143(18.7)$ & $132(20.5)$ & $11(9.2)$ & \\
\hline $35-44$ & $172(22.5)$ & $156(24.2)$ & $16(13.3)$ & \\
\hline $45-54$ & $156(20.4)$ & $138(21.4)$ & $18(15.0)$ & \\
\hline $55-64$ & $116(15.2)$ & $86(13.4)$ & $30(25.0)$ & \\
\hline 65 and older & $113(14.8)$ & $69(10.7)$ & $44(36.7)$ & \\
\hline Total & 764 & 644 & 120 & \\
\hline \multicolumn{5}{|l|}{ Gender } \\
\hline Female & $505(65.6)$ & $433(66.8)$ & $72(59.0)$ & \multirow[t]{4}{*}{$p=0.188$} \\
\hline Male & $255(33.1)$ & 207 (31.9) & $48(39.3)$ & \\
\hline Transgender & $10(1.3)$ & $8(1.2)$ & $2(1.6)$ & \\
\hline Total & 770 & 648 & 122 & \\
\hline \multicolumn{5}{|l|}{ Education } \\
\hline University or college graduate & $442(59.4)$ & $353(56.4)$ & $89(75.4)$ & \multirow[t]{5}{*}{$p=0.001$} \\
\hline Some college or university & $149(20.0)$ & $132(21.1)$ & $17(14.4)$ & \\
\hline High School & $117(15.7)$ & $107(17.1)$ & $10(8.5)$ & \\
\hline Less than high school & $36(4.8)$ & $34(5.4)$ & $2(1.7)$ & \\
\hline Total & 744 & 626 & 118 & \\
\hline \multicolumn{5}{|l|}{ Employment } \\
\hline Employed, full time & $293(39.4)$ & $244(38.9)$ & $49(42.2)$ & \multirow[t]{6}{*}{$p<0.001$} \\
\hline Employed, part time & $131(17.6)$ & $119(19.0)$ & $12(10.3)$ & \\
\hline Unemployed & $93(12.5)$ & $89(14.2)$ & $4(3.4)$ & \\
\hline Retired & $121(16.3)$ & $73(11.6)$ & $48(41.4)$ & \\
\hline Unable to work & $105(14.1)$ & $102(16.3)$ & $3(2.6)$ & \\
\hline Total & 743 & 627 & 116 & \\
\hline \multicolumn{5}{|l|}{ Monthly Household Income } \\
\hline Less than $\$ 650.00$ & $29(4.0)$ & $28(4.6)$ & $1(0.9)$ & \multirow[t]{5}{*}{$p<0.001$} \\
\hline$\$ 700.00$ to $\$ 1800.00$ & $217(29.9)$ & $210(34.4)$ & $7(6.1)$ & \\
\hline$\$ 1850.00$ to $\$ 3000.00$ & $158(21.8)$ & $141(23.1)$ & $17(14.9)$ & \\
\hline Above $\$ 3000.00$ & $321(44.3)$ & $232(38.0)$ & $89(78.1)$ & \\
\hline Total & 725 & 611 & 114 & \\
\hline \multicolumn{5}{|l|}{ Benefits } \\
\hline CPP-R & $75(9.7)$ & $46(7.1)$ & $29(23.8)$ & \multirow[t]{6}{*}{$p<0.001$} \\
\hline CPP-D / ODSP & $101(13.1)$ & 99 (15.3) & $2(1.6)$ & \\
\hline El / El Sick Benefits & $47(6.1)$ & $44(6.8)$ & $3(2.5)$ & \\
\hline Other (e.g. Ontario Works) & $120(15.6)$ & $107(16.5)$ & $13(10.7)$ & \\
\hline No response & $427(55.5)$ & $352(54.3)$ & $75(61.5)$ & \\
\hline Total & 770 & 648 & 122 & \\
\hline \multicolumn{5}{|l|}{ Housing } \\
\hline Owns residence & $392(51.0)$ & $288(44.5)$ & $104(85.2)$ & \multirow[t]{2}{*}{$p<0.001$} \\
\hline Rents residence & $289(37.6)$ & $277(42.8)$ & $12(9.8)$ & \\
\hline
\end{tabular}


Table 1 Socio-demographic characteristics of participants with and without legal needs and comparisons between these two groups (Continued)

\begin{tabular}{|c|c|c|c|c|}
\hline & $\begin{array}{l}\text { All survey respondents } \\
N=770 \\
\mathrm{n}(\%)\end{array}$ & $\begin{array}{l}\text { At least one legal need }{ }^{1} \\
n=648 \\
\mathrm{n}(\%)\end{array}$ & $\begin{array}{l}\text { No legal needs } \\
n=122 \\
n(\%)\end{array}$ & $\begin{array}{l}\text { Has legal need versus } \\
\text { No legal needs } \\
p \text { value }^{2}\end{array}$ \\
\hline Lives with friends or family & $67(8.7)$ & $62(9.6)$ & $5(4.1)$ & \\
\hline Other & $21(2.7)$ & $20(3.1)$ & $1(0.8)$ & \\
\hline Total & 769 & 647 & 122 & \\
\hline \multicolumn{5}{|l|}{ Relationship Status } \\
\hline Married & $321(42.7)$ & $240(37.9)$ & $81(68.1)$ & $p<0.001$ \\
\hline Common law or cohabiting & $94(12.5)$ & $87(13.7)$ & $7(5.9)$ & \\
\hline Single (never married) & $178(23.7)$ & $168(26.5)$ & $10(8.4)$ & \\
\hline Widowed & $33(4.4)$ & $24(3.8)$ & $9(7.6)$ & \\
\hline Divorced & $73(9.7)$ & $64(10.1)$ & $9(7.6)$ & \\
\hline Separated & $53(7.0)$ & $50(7.9)$ & $3(2.5)$ & \\
\hline Total & 752 & 633 & 119 & \\
\hline \multicolumn{5}{|l|}{ Citizenship Status } \\
\hline Canadian Citizen & $691(92.8)$ & $576(91.9)$ & $115(97.5)$ & $p=0.032$ \\
\hline Other & $54(7.2)$ & $51(8.1)$ & $3(2.5)$ & \\
\hline Total & 745 & 627 & 118 & \\
\hline \multicolumn{5}{|l|}{ Race } \\
\hline White/Caucasian & $612(82.1)$ & $498(79.3)$ & $114(97.4)$ & $p<0.001$ \\
\hline Other & $133(17.9)$ & $130(20.7)$ & $3(2.6)$ & \\
\hline Total & 745 & 628 & 117 & \\
\hline
\end{tabular}

Notes: ${ }^{1}$ Participants with legal needs indicated by the Legal Health Check-Up survey; ${ }^{2} p$-value from Fisher's Exact Test; CPP-R Canadian Pension Plan, retired, $C P P$ $D$ Canadian Pension Plan, disability, ODSP Ontario Disability Support Plan, El Employment Insurance

0.214) (see Table 2). Those who had a legal need had a higher rate of inability to afford medication $(25.5 \%$ versus $3.3 \%)$, inability to afford food ( $14.3 \%$ versus $0.9 \%)$, and housing insecurity (12.6\% versus $2.7 \%)$. In the subset of 283 participants who had household size available from a follow-up survey, $61.9 \%(n=140)$ of those with a legal need had a household income below LIM-50, compared to $15.8 \%(n=9)$ of those without a legal need. In those with a legal need, 9.7\% $(n=60)$ had a self-reported health status of 'poor' compared to $0 \%$ of those without a legal need. Also, the most frequent response for self-reported health status was 'fair or good' among those with a legal need $(53.9 \%, n=335)$, while the most frequent response was 'very good or excellent' among those without a legal need $(62.1 \%, n=72)$. Finally, the EQ-5D-3L tool measuring five domains of quality of life showed those with a legal need more frequently had difficulty with mobility (30.6\% versus $17.2 \%)$, self-care $(9.1 \%$ versus $1.7 \%)$, performing usual activities (38.3\% versus $15.5 \%$ ), and anxiety/ depression (55.6\% versus $31.6 \%$ ).

\section{Legal needs in primary care}

Using the Legal Health Check-Up tool, 2648 legal needs were identified through screening and 648 (84.2\%) participants had at least one legal need. There was an average of 3.44 $(\mathrm{SD}=3.42)$ legal needs per participant screened and an average of $4.09(\mathrm{SD}=3.35)$ legal needs per participant who had at least one legal issue; see Fig. 1 for the distribution of legal needs across participants screened. The types of legal needs identified were family/ community $(82.9 \%$ of respondents, $n=537)$, income $(56 \%$, $n=363)$, employment (46.9\%, $n=304)$, housing (40.3\%, $n=$ 261 ), and health $(34.9 \%, n=226)$. Details on the subcategories for each of these five types of legal needs and their frequencies can be seen in Table 3. Notably, 75.0\% $(n=486)$ of respondents did not have a will, $45.2 \%(n=293)$ had trouble making ends meet, $31.2 \%(n=202)$ did not have someone to make health decisions if they become unable, 30.1\% ( $n=$ $195)$ had been hurt at work, $24.8 \%(n=161)$ needed help getting or keeping their benefits, and $24.1 \%(n=156)$ were in a relationship where someone was trying to control them.

The Legal Health Check-Up tool also identified that all 770 participants screened (100\%) had at least one issue related to social determinants of health that could be referred to the system navigator (e.g. assistance accessing subsidized daycare). A total of 5371 issues were identified through screening and there was a mean of 6.98 issues $(\mathrm{SD}=4.29)$ per participant screened. 
Table 2 Poverty indicators, self-reported health status, and quality of life in participants with and without legal needs and comparisons between these two groups

\begin{tabular}{|c|c|c|c|c|}
\hline & $\begin{array}{l}\text { All survey respondents } \\
N=770 \\
\mathrm{n}(\%)\end{array}$ & $\begin{array}{l}\text { At least one legal need }{ }^{1} \\
n=648 \\
n(\%)\end{array}$ & $\begin{array}{l}\text { No legal needs } \\
n=122 \\
n(\%)\end{array}$ & $\begin{array}{l}\text { Has legal need versus } \\
\text { No legal needs } \\
p \text {-value }^{2}\end{array}$ \\
\hline \multicolumn{5}{|c|}{ Household Income: Low-Income Measure $50^{3}$} \\
\hline Above LIM 503 & $134(47.3)$ & $86(38.1)$ & $48(84.2)$ & $p<0.001$ \\
\hline Below LIM $50^{3}$ & $149(52.7)$ & $140(61.9)$ & $9(15.8)$ & \\
\hline Total & 283 & 226 & 57 & \\
\hline \multicolumn{5}{|l|}{ Income Insecurity } \\
\hline Yes & $293(38.1)$ & $293(45.2)$ & $0(0.0)$ & Not applicable ${ }^{4}$ \\
\hline No & $477(61.9)$ & $355(54.8)$ & $122(100)$ & \\
\hline Total & 770 & 648 & 122 & \\
\hline \multicolumn{5}{|l|}{ Cannot afford medication } \\
\hline Yes & $169(21.9)$ & $165(25.5)$ & $4(3.3)$ & $p<0.001$ \\
\hline No & $601(78.1)$ & $483(74.5)$ & $118(96.7)$ & \\
\hline Total & 770 & 648 & 122 & \\
\hline \multicolumn{5}{|l|}{ Food Insecurity } \\
\hline Yes & $89(12.2)$ & $88(14.3)$ & $1(0.9)$ & $p<0.001$ \\
\hline No & $641(87.8)$ & $529(85.7)$ & $112(99.1)$ & \\
\hline Total & 730 & 617 & 113 & \\
\hline \multicolumn{5}{|l|}{ Housing Insecurity } \\
\hline Yes & $80(11.0)$ & $77(12.6)$ & $3(2.7)$ & $p=0.001$ \\
\hline No & $645(89.0)$ & $536(87.4)$ & $109(97.3)$ & \\
\hline Total & 725 & 613 & 112 & \\
\hline \multicolumn{5}{|l|}{ Self-reported Health Status } \\
\hline Excellent/Nery good & $298(40.4)$ & $226(36.4)$ & $72(62.1)$ & $p<0.001$ \\
\hline Good/Fair & $379(51.4)$ & $335(53.9)$ & $44(37.9)$ & \\
\hline Poor & $60(8.1)$ & $60(9.7)$ & $0(0.0)$ & \\
\hline Total & 737 & 621 & 116 & \\
\hline \multicolumn{5}{|l|}{ Quality of Life } \\
\hline \multicolumn{5}{|l|}{ Mobility } \\
\hline No problem & $522(71.5)$ & $426(69.4)$ & $96(82.8)$ & $p=0.003$ \\
\hline Some/Severe problems & $208(28.5)$ & $188(30.6)$ & $20(17.2)$ & \\
\hline Total & 730 & 614 & 116 & \\
\hline \multicolumn{5}{|l|}{ Self-care } \\
\hline No problem & $670(92.0)$ & $557(90.9)$ & $113(98.3)$ & $p=0.004$ \\
\hline Some/Severe problems & $58(8.0)$ & $56(9.1)$ & $2(1.7)$ & \\
\hline Total & 728 & 613 & 115 & \\
\hline \multicolumn{5}{|l|}{ Performing usual activities } \\
\hline No difficulty & $477(65.3)$ & $379(61.7)$ & $98(84.5)$ & $p<0.001$ \\
\hline Some/Severe difficulty & $253(34.7)$ & $235(38.3)$ & $18(15.5)$ & \\
\hline Total & 730 & 614 & 106 & \\
\hline \multicolumn{5}{|l|}{ Pain and discomfort } \\
\hline None & $288(39.4)$ & $236(38.4)$ & $52(44.8)$ & $p=0.214$ \\
\hline Some/Severe & $443(60.6)$ & $379(61.6)$ & $64(55.2)$ & \\
\hline Total & 731 & 615 & 116 & \\
\hline
\end{tabular}


Table 2 Poverty indicators, self-reported health status, and quality of life in participants with and without legal needs and comparisons between these two groups (Continued)

\begin{tabular}{|c|c|c|c|c|}
\hline & $\begin{array}{l}\text { All survey respondents } \\
N=770 \\
\mathrm{n}(\%)\end{array}$ & $\begin{array}{l}\text { At least one legal need }{ }^{1} \\
n=648 \\
n(\%)\end{array}$ & $\begin{array}{l}\text { No legal needs } \\
n=122 \\
\mathrm{n}(\%)\end{array}$ & $\begin{array}{l}\text { Has legal need versus } \\
\text { No legal needs } \\
p \text {-value }{ }^{2}\end{array}$ \\
\hline \multicolumn{5}{|c|}{ Anxiety and depression } \\
\hline None & $349(48.1)$ & $271(44.4)$ & $78(68.4)$ & $p<0.001$ \\
\hline Some/Severe & $376(51.9)$ & $340(55.6)$ & $36(31.6)$ & \\
\hline Total & 725 & 611 & 114 & \\
\hline
\end{tabular}

Notes: ${ }^{1}$ Participants with legal needs indicated by the Legal Health Check-Up survey; ${ }^{2} p$-value from Fisher's Exact Test; ${ }^{3}$ Low Income Measure 50 (LIM-50) is the threshold for median (50th percentile) household income, adjusted for household size. Household size was asked on a follow-up survey, not baseline, so LIM-50 could only be calculated for 283 participants. ${ }^{4}$ Income insecurity was considered a legal need on the screening survey, hence this poverty indicator had a frequency of $0 \%$ for those without a legal need and it was not appropriate to run significance testing for this measure

\section{Legal clinic attendees}

Of the 648 participants identified through screening to have a legal need, 94 (14.5\%) booked an appointment with the LHC; of the 94 who booked, 69 (73.4\%) attended the LHC once and five (5.3\%) attended twice. In Table 4, the socio-demographic characteristics of those who booked and those who attended the LHC are provided. Since the objective of this study was not to compare these groups, there were no statistical comparisons made, however the frequencies for each group have been reported for transparency and completeness. Similarly, the poverty indicators, self-reported health status, quality of life, and types of legal needs have been reported for both of these groups in Tables 5 and 6.

In the 69 participants who did attend the LHC, the majority were female $(59.4 \%, n=41)$, did not complete post-secondary education (59\%, $n=36)$, were not employed full-time $(89.1 \%, n=57)$, were receiving benefits $(69.6 \%, n=48)$, did not own their residence $(79.3 \%$, $n=55)$, were not married or common-law $(72.3 \%, n=47)$, were Canadian citizens $(85.5 \%, n=53)$, and were white $(69.2 \%, n=45)$. The $18-24$ year old age category had the lowest representation $(7.4 \%, \mathrm{n}=5)$ and both the 35-44 and 45-54 year old categories had the highest representation (25.0\% and $n=17$ for both age categories). Please see Table 4 for the full demographic profile.

The poverty indicators were common among LHC attendees (see Table 5), with $78.3 \%(n=54)$ reporting income insecurity, $58.0 \%(n=40)$ unable to afford their medication, $56.9 \%(n=37)$ having food insecurity, and $39.1 \%(n=25)$ having housing insecurity. In the subset of 27 respondents who provided household size, 88.9\% $(n=24)$ had a household income below the LIM-50 threshold. Self-Reported Health Status in LHC attendees was quite low, with only 7.7\% $(\mathrm{n}=5)$ reporting 'excellent' or 'very good' health, $67.7 \%(n=44)$ reporting 'good' or 'fair' health, and $24.6 \%(n=16)$ reporting 'poor' health. Quality of life was similarly low among attendees with

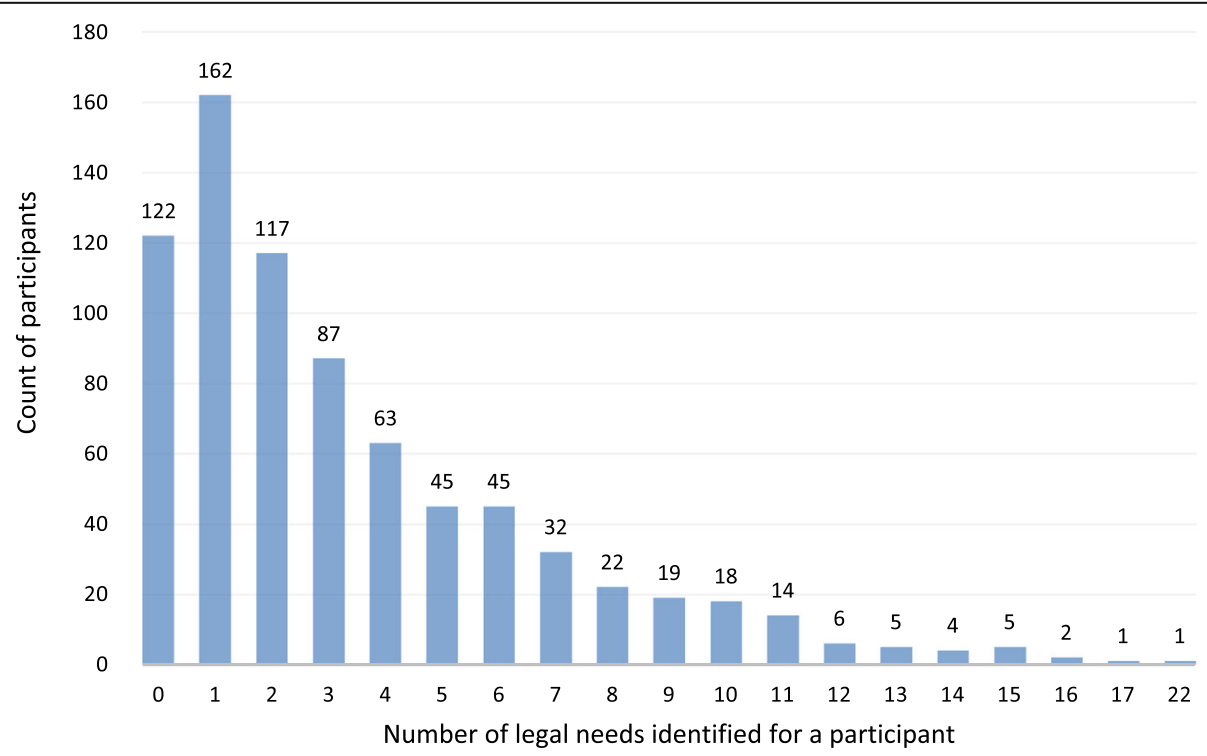

Fig. 1 Distribution of legal needs $(n=2648)$ across participants $(n=770)$ as identified through Legal Health Check-up survey screening 
Table 3 Types of legal needs identified using the Legal Health Check-up Survey

Indicated at least one legal need $(n=648)$

\begin{tabular}{|c|c|}
\hline Type of Legal Need & n (\%) \\
\hline Income & $363(56.0)^{2}$ \\
\hline 'Trouble making ends meet' & $293(45.2)$ \\
\hline Needing help getting or keeping benefits & $161(24.8)$ \\
\hline Someone taking their money or possessions without permission & $42(6.5)$ \\
\hline Medical review date for ODSP & $18(2.8)$ \\
\hline Other/unspecified income issue & $92(14.2)$ \\
\hline
\end{tabular}

\section{Housing}

Problems with home repairs, heat not working, bed bugs, etc.

Late with rent this year

Problems with neighbours

Denied a rental unit due to discrimination

Being harassed or discriminated by their landlord

Worried rent subsidy will be cancelled

Behind with rent

Served eviction papers

Court order affecting where or with whom they can live

\section{Employment}

Has been hurt at work

Having trouble finding work due to discrimination

Has been harassed by your employer or colleagues

Current or past employer owes them money

Other/unspecified employment issue

\section{Health}

Does not have someone to make health decisions if they are unable to do so

\section{Family/Community}

Does not have a will

Relationship where someone tries to control them

Going through a divorce or separation

Problems with child support or access

Trouble bringing family members to Canada

Trouble attaining citizenship

Note: ${ }^{a}$ Respondent indicated at least one item from the respective list

85.9\% $(n=64)$ reporting pain or discomfort, $78.1 \%(n=$ 50) difficulty performing their usual activities, $74.6 \%$ $(n=47)$ anxiety or depression, $65.6 \%(n=42)$ mobility problems, and $25.0 \%(\mathrm{n}=16)$ problems with self-care (e.g. dressing unassisted).

Looking at the types of legal needs in attendees (see Table 6), $95.7 \%(n=66)$ had a legal need related to family/community, $89.9 \%(n=62)$ income, $75.4 \%(n=$ 52) employment, 69.6\% $(n=48)$ housing, and 59.4\% $(n=$ 41) health. The frequencies for each subcategory of legal need can be seen in Table 6. Notably, 85.5\% $(n=59)$ of attendees did not have a will, $78.3 \%(n=54)$ had trouble making ends meet, $56.5 \%(n=39)$ needed help getting or keeping their benefits, $53.6 \%(n=37)$ did not have 
Table 4 Socio-demographic characteristics of participants who booked and attended Legal Health Clinic appointments

\section{Booked appointment}

Age

$18-24$

25-34

$35-44$

$45-54$

55-64

65 and older

Total

\section{Gender}

Female
Male
Transgender
Total
Education
University or college graduate
Some college or university
High School
Less than high school
Total

\section{Employment}

Employed, full time
Employed, part time
Unemployed
Retired
Unable to work
otal

Monthly Household Income

$$
\begin{aligned}
& \text { Less than } \$ 650.00 \\
& \$ 700.00 \text { to } \$ 1800.00 \\
& \$ 1850.00 \text { to } \$ 3000.00 \\
& \text { Above } \$ 3000.00 \\
& \text { Total }
\end{aligned}
$$

Benefits

CPP-R
CPP-D / ODSP
El / El Sick Benefits
Other (e.g. Ontario Works)
No response
Total

\section{Housing}

Owns residence

Rents residence $n=94$

n (\%)

$$
\begin{aligned}
& 9(9.8) \\
& 19(20.7) \\
& 24(26.1) \\
& 21(22.8) \\
& 12(13.0) \\
& 7(7.6) \\
& 92
\end{aligned}
$$

\author{
57 (60.6) \\ 34 (36.2) \\ $3(3.2)$ \\ 94
}

Attended appointment $n=69$

n (\%)
$5(7.4)$
12 (17.6)
17 (25.0)
$17(25.0)$
$10(14.7)$
7 (10.3)

68

$41(59.4)$
$25(36.2)$
$3(4.3)$
69

35 (40.7)

25 (41.0)

24 (27.9)

16 (26.2)

17 (19.8)

$14(23.0)$

10 (11.6)

86

$6(9.8)$

61

$13(14.6)$
$16(18.0)$
$21(23.6)$
$8(9.0)$
$31(34.8)$
89

7 (10.9)

14 (21.9)

16 (25.0)

8 (12.5)

19 (29.7)

64

$10(11.1)$
$51(56.7)$
$20(22.2)$
$9(10.0)$
90

$6(9.2)$

40 (61.5)

$13(20.0)$

$6(9.2)$

65

$5(5.3)$
$29(30.9)$
$6(6.4)$
$24(25.5)$
$30(31.9)$
94

4 (5.8)

22 (31.9)

5 (7.2)

17 (24.6)

$21(30.4)$

69

20 (21.3)

14 (20.3)

58 (61.7)

45 (65.2) 
Table 4 Socio-demographic characteristics of participants who booked and attended Legal Health Clinic appointments (Continued)

\begin{tabular}{|c|c|c|}
\hline & $\begin{array}{l}\text { Booked appointment } \\
n=94\end{array}$ & $\begin{array}{l}\text { Attended appointment } \\
n=69\end{array}$ \\
\hline & n (\%) & n (\%) \\
\hline Lives with friends or family & $8(8.5)$ & $5(7.2)$ \\
\hline Other & $8(8.5)$ & $5(7.2)$ \\
\hline Total & 94 & 69 \\
\hline \multicolumn{3}{|l|}{ Relationship Status } \\
\hline Married & $16(17.8)$ & $14(21.5)$ \\
\hline Common law or cohabiting & $10(11.1)$ & $4(6.2)$ \\
\hline Single (never married) & $31(34.4)$ & $20(30.8)$ \\
\hline Widowed & $2(2.2)$ & $2(3.1)$ \\
\hline Divorced & $17(18.9)$ & $15(23.1)$ \\
\hline Separated & $14(7.1)$ & $10(15.4)$ \\
\hline Total & 90 & 65 \\
\hline \multicolumn{3}{|l|}{ Citizenship Status } \\
\hline Canadian Citizen & $77(88.5)$ & $53(85.5)$ \\
\hline Other & $10(11.5)$ & $9(14.5)$ \\
\hline Total & 87 & 62 \\
\hline \multicolumn{3}{|l|}{ Race } \\
\hline White/Caucasian & $63(71.6)$ & $45(69.2)$ \\
\hline Other & $25(28.4)$ & $20(30.8)$ \\
\hline Total & 88 & 65 \\
\hline
\end{tabular}

someone to make health decisions if they become unable, $43.5 \%(n=30)$ had been hurt at work, $43.5 \%(n=$ 30) were in a relationship where someone was trying to control them, $36.2 \%(n=25)$ had problems with their home (e.g. heat not working), and $36.2 \%(\mathrm{n}=25)$ were having trouble finding work due to discrimination.

Logistic regression was used to determine the demographic characteristics, poverty indicators, health status, and quality of life domains associated with a participant choosing to attend the LHC or not. Due to a high correlation between employment status and receiving benefits, only employment status was retained in the model. All participants who had a legal need and complete data for the modelled variables were included in the analysis $(n=561$; see Table 7). Participants with legal needs had significantly higher odds of attending the LHC if they were an ethnicity that was not white $(\mathrm{OR}=2.48 ; 95 \% \mathrm{CI}$ 1.14-5.39), did not have Canadian citizenship (OR = 4.40; 95\% CI 1.48-13.07), had housing insecurity ( $\mathrm{OR}=$ 3.33; 95\% CI 1.53-7.24), and had difficulty performing their usual activities $(\mathrm{OR}=2.83 ; 95 \%$ CI $1.08-7.43)$.

As a result of the LHC consultations, $58.0 \%(n=40)$ were referred to either LAO or HCLC, depending on their income level and area of law needed, 21.74\% ( $n=$ $15)$ were referred to a private lawyer, and one case was taken on by the LHC lawyer. This does not include cases that were taken on by lawyers at LAO or HCLC postreferral. Also, $47.8 \%(n=33)$ of participants were provided education and $29.0 \%(n=20)$ of participants were provided resources.

\section{Discussion}

The FHT-based legal clinic appears to be fulfilling a need by providing more equitable access to legal services for vulnerable populations. To date, the USA has been the primary source of research literature on medicallegal partnerships; although there have also been medical-legal partnerships focused on geriatrics, obstetrics and gynecology, oncology and family medicine in the USA, most have been in the area of pediatrics [1]. The current study describes a novel medico-legal partnership in a Canadian family medicine clinic. Lawyers from LAO and HCLC staffed the program successfully for the 6-month study, provided consultations to $69 \mathrm{pa}$ tients, and have continued to deliver their services to additional FHT patients through the LHC beyond the study time frame. This study found that four out of every five patients in this primary care setting had at least one legal need that could affect their health, therefore the LHC is playing an important role in addressing 
Table 5 Poverty indicators, self-reported health status, and quality of life in participants who booked and attended a Legal Health Clinic appointment

Booked appointment

$n=94$

n (\%)

Household Income: Low-Income Measure $50^{3}$
$4(12.5)$

$28(87.5)$

32

Yes

No

Total

$74(78.7)$

$15(21.7)$

$20(21.3)$

94

69

Afford to Buy Medication

Yes
No
Total

Food Insecurity

Yes

Housing Insecurity

Yes
No
Total

Self-Reported Health Status

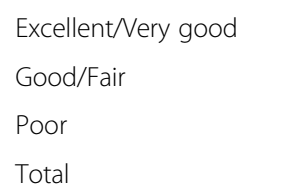

\section{Quality of Life}

\section{Mobility}

No problem

$\begin{array}{ll}32(36.8) & 25(39.1) \\ 55(63.2) & 39(60.9) \\ 88 & 64\end{array}$

Self-care
No problem
Some/Severe problems
Total

86

64

Performing usual activities

$$
\text { No difficulty }
$$

Total

86

$$
\begin{aligned}
& 48(75.0) \\
& 16(25.0)
\end{aligned}
$$

64

$$
\begin{aligned}
& 14(21.9) \\
& 50(78.1) \\
& 64
\end{aligned}
$$

\section{Pain and discomfort}

None 
Table 5 Poverty indicators, self-reported health status, and quality of life in participants who booked and attended a Legal Health Clinic appointment (Continued)

\begin{tabular}{lll}
\hline & $\begin{array}{l}\text { Booked appointment } \\
\mathbf{n = 9 4} \\
\mathbf{n}(\%)\end{array}$ & $\begin{array}{l}\text { Attended appointment } \\
\mathbf{n = 6 9} \\
\mathbf{n}(\%)\end{array}$ \\
\hline Anxiety and depression & & $16(25.4)$ \\
None & $18(21.2)$ & $47(74.6)$ \\
Some/Severe & $67(78.8)$ & 63 \\
Total & 85 & 63 \\
\hline
\end{tabular}

Note: ${ }^{1}$ Participants with legal needs indicated by the Legal Health Check-Up survey; ${ }^{2} p$-value from Fisher's Exact Test; ${ }^{3}$ Low Income Measure 50 (LIM-50) is the threshold for median (50th percentile) household income, adjusted for household size. Household size was asked on a follow-up survey, not baseline, so LIM-50 could only be calculated for 32 participants

this gap in access to legal services and may improve health outcomes in the long term.

The LHC was purposefully developed in collaboration with LAO and HCLC to facilitate both immediate feasibility and long-term sustainability. This ensured that organisational attitudes were positive towards the LHC and so funding was made available. At the time of writing, the service has continued for 3 years, with a slight alteration in the participant flow process. Instead of being approached in the waiting room by a research assistant, they are now identified during new patient registration, at which point patients are asked to complete the screening tool, and those identified with unmet legal needs are asked if they would like an LHC appointment. For existing patients, physicians or other health professionals from the FHT can refer patients to the LHC if a new need is identified. In order to make the LHC more sustainable, and because family physicians felt that they were accurately able to assess potential legal needs, the screening tool was dropped for these types of direct referrals, though new patients to the clinic are all screened by clinic staff using the screening tool. Also, there are posters and on-screen advertisements in the waiting areas to raise awareness among patients that the LHC is available and free for them to access.

In the study setting, a FHT in Hamilton, Ontario, 84\% of patients screened had unmet legal needs that could benefit from the LHC intervention, with an average of 3.4 legal needs per patient screened. Given that approximately half of patients in the waiting area had a household income below LIM 50 (poverty threshold), the rate of observed legal needs is similar to those found in studies from the USA and Canada suggesting that each lowincome household has three or more legal needs per year $[3,4,29,30]$. The types of legal issues identified through the Legal Health Check-Up in the current study were family/community, income, housing, employment, and health. These are in line with those identified in the Canadian pediatric medical-legal model, where the most common legal issues encountered were: family concerns, immigration/refugee, education, employment, income and housing [2]. Similarly, a report on the civil legal needs of Ontarians has cited that the most common legal problems identified among low and middle income individuals include: family relationship problems, wills and powers of attorney, housing, real estate, and employment (listed from most common to least common) [29]. In contrast, in the United States, the most common legal issues encountered were social security, health insurance coverage, advance directives, food stamps, family concerns, and housing [1]. These legal needs are quite different from those found in the Canadian studies (the current study and the study in pediatrics), [2] highlighting the differences between the USA and Canadian healthcare contexts and the importance of Canadianbased research on this topic to inform future medicallegal partnerships in Canada.

We also found that those with a legal need were more vulnerable compared to those without, with higher rates of housing insecurity, food insecurity, and income insecurity. It has been suggested in Canada that the vulnerability of this population makes them less likely to seek legal assistance, [4] however trusted healthcare professionals can facilitate this introduction, as observed in the current study. When comparing our study participants who attended the legal clinic to those with legal needs who did not attend, there is a clear difference in SES between the two groups. The population that chose to attend had lower income levels, as well as unstable employment and residence. Participants who were not Canadian citizens had significantly higher odds of attending an appointment than Canadians. These results are consistent with the demographic profile of participants in other studies that have implemented medicallegal partnerships and demonstrate the LHC's success in providing more equitable access $[2,30]$. This is expected as vulnerable populations that are negatively impacted by the social determinants of health are more likely to have unmet legal needs and are unable to afford a lawyer $[15,29]$. It is these legal needs, that when addressed, can improve the social determinants of health and result in positive health outcomes $[7,13,14]$.

One of the limitations of this paper is that the Legal Clinic was only provided in an academic FHT, located in 
Table 6 Types of legal needs identified in participants booked and attended a Legal Health Clinic appointment

\begin{tabular}{|c|c|c|}
\hline Type of Legal Need & $\begin{array}{l}\text { Booked appointment } \\
n=94 \\
\mathrm{n}(\%)\end{array}$ & $\begin{array}{l}\text { Attended appointment } \\
n=69 \\
\mathrm{n}(\%)\end{array}$ \\
\hline Income & $82(87.2)^{a}$ & $62(89.9)^{a}$ \\
\hline 'Trouble making ends meet' & $74(78.7)$ & $54(78.3)$ \\
\hline Needing help getting or keeping benefits & $53(56.4)$ & $39(56.5)$ \\
\hline Someone taking their money or possessions without permission & $21(22.3)$ & $14(20.3)$ \\
\hline Medical review date for ODSP & $5(5.3)$ & $4(5.8)$ \\
\hline Other/unspecified income issue & $37(39.4)$ & $30(43.5)$ \\
\hline Housing & $67(71.3)^{\mathrm{a}}$ & $48(69.6)^{a}$ \\
\hline Problems with home repairs, heat not working, bed bugs, etc. & $35(37.2)$ & $25(36.2)$ \\
\hline Denied a rental unit due to discrimination & $27(28.7)$ & $19(27.5)$ \\
\hline Late with rent this year & $24(25.5)$ & $14(20.3)$ \\
\hline Being harassed or discriminated by their landlord & $18(19.1)$ & $14(20.3)$ \\
\hline Worried rent subsidy will be cancelled & $13(13.8)$ & $9(13.0)$ \\
\hline Being threatened with eviction & $11(11.7)$ & $6(8.7)$ \\
\hline Served eviction papers & $8(8.5)$ & $6(8.7)$ \\
\hline Court order affecting where or with whom they can live & $8(8.5)$ & $5(7.2)$ \\
\hline Behind with rent & $7(7.4)$ & $3(4.3)$ \\
\hline Other/unspecified housing issue & $23(24.5)$ & $17(24.6)$ \\
\hline Employment & $66(70.2)^{a}$ & $52(75.4)^{\mathrm{a}}$ \\
\hline Has been hurt at work & $38(40.4)$ & $30(43.5)$ \\
\hline Having trouble finding work due to discrimination & $32(34.0)$ & $25(36.2)$ \\
\hline Current or past employer owes them money & $9(9.6)$ & $9(13.0)$ \\
\hline Has been harassed by your employer or colleagues & $9(9.6)$ & $8(11.6)$ \\
\hline Other/unspecified employment issue & $16(17.0)$ & $15(21.7)$ \\
\hline Health & $53(56.4)^{a}$ & $41(59.4)^{\mathrm{a}}$ \\
\hline Does not have someone to make health decisions if they are unable to do so & $49(52.1)$ & $37(53.6)$ \\
\hline Other/unspecified health issue & $13(13.8)$ & $12(17.4)$ \\
\hline Family/Community & $91(96.8)^{a}$ & $66(95.7)^{a}$ \\
\hline Does not have a will & $80(85.1)$ & $59(85.5)$ \\
\hline Relationship where someone tries to control them & $46(48.9)$ & $30(43.5)$ \\
\hline Problems with child support or access & $24(25.5)$ & $14(20.3)$ \\
\hline Going through a divorce or separation & $18(19.1)$ & $14(20.3)$ \\
\hline Trouble bringing family members to Canada & $13(13.8)$ & $9(13.0)$ \\
\hline Trouble attaining citizenship & $5(5.3)$ & $5(7.2)$ \\
\hline Other/unspecified family or community issue & $14(14.9)$ & $11(15.9)$ \\
\hline
\end{tabular}

Note: ${ }^{a}$ Respondent indicated at least one item from the respective list

the inner city, urban setting of Hamilton, Ontario. It is possible that in different settings the results would have been different. It is likely though, that the results of this paper are generalizable to other inner cities settings with similar populations.

The McMaster Family Practice Legal Clinic has important implications for the future health of patients, as well as for clinical practice. The Legal Clinic is taking an "upstream" approach to addressing the social determinants of health by ensuring patients receive timely access to the legal services for which they otherwise may have not received help. By helping patients overcome the barrier in accessing legal services and therefore addressing underlying social causes of adverse health outcomes, and 
Table 7 Logistic regression of participant characteristics associated with attending the Legal Health Clinic

\begin{tabular}{|c|c|c|c|c|}
\hline \multirow[t]{2}{*}{ Variable } & & \multicolumn{3}{|c|}{$\begin{array}{l}\text { Attended the Legal Health Clinic }(n=59) \\
\text { Versus Did not attend }(n=502)\end{array}$} \\
\hline & & OR & $95 \% \mathrm{Cl}$ & $p$-value \\
\hline \multirow[t]{3}{*}{ Gender } & Female & REF & - & - \\
\hline & Male & 1.11 & $0.55,2.26$ & 0.766 \\
\hline & Transgender & 6.74 & $0.69,66.30$ & 0.102 \\
\hline \multirow[t]{6}{*}{ Age Category } & 18-24 years & REF & - & - \\
\hline & $25-34$ years & 0.75 & $0.19,3.03$ & 0.686 \\
\hline & $35-44$ years & 1.18 & $0.31,4.53$ & 0.811 \\
\hline & $45-55$ years & 0.69 & $0.18,2.68$ & 0.592 \\
\hline & $55-64$ years & 1.02 & $0.24,4.43$ & 0.976 \\
\hline & 65 and older & 0.95 & $0.18,4.93$ & 0.950 \\
\hline \multirow[t]{3}{*}{ Ethnicity } & White & REF & - & - \\
\hline & Other ethnicity & 2.48 & $1.14,5.39$ & 0.022 \\
\hline & No response & 6.04 & $0.338,96.49$ & 0.204 \\
\hline \multirow[t]{3}{*}{ Citizenship } & Canadian & REF & - & - \\
\hline & Other citizenship & 4.40 & $1.48,13.07$ & 0.008 \\
\hline & No response & 1.02 & $0.05,23.27$ & 0.989 \\
\hline \multirow[t]{2}{*}{ Relationship Status } & Married/Common Law & REF & - & - \\
\hline & Other response & 1.01 & $0.45,2.24$ & 0.988 \\
\hline \multirow[t]{3}{*}{ Education } & High School or below & REF & - & - \\
\hline & Any post-secondary & 0.99 & $0.45,2.18$ & 0.976 \\
\hline & No response & 7.97 & $0.46,139.21$ & 0.155 \\
\hline \multirow[t]{2}{*}{ Employment } & Employed & REF & - & - \\
\hline & Not employed & 1.25 & $0.55,2.83$ & 0.594 \\
\hline \multirow[t]{4}{*}{ Monthly Household Income } & Less than $\$ 650$ & REF & - & - \\
\hline & $\$ 700-\$ 1800$ & 0.62 & $0.17,2.18$ & 0.446 \\
\hline & $\$ 1850-\$ 3000$ & 0.36 & $0.09,1.51$ & 0.162 \\
\hline & More than $\$ 3000$ & 0.36 & $0.07,1.89$ & 0.226 \\
\hline \multirow[t]{2}{*}{ Housing } & Owns their home & REF & - & - \\
\hline & Does not own their home & 1.48 & $0.60,3.63$ & 0.397 \\
\hline \multirow[t]{2}{*}{ Income Insecure } & No & REF & - & - \\
\hline & Yes & 1.95 & $0.78,4.93$ & 0.156 \\
\hline \multirow[t]{2}{*}{ Food Insecure } & No & REF & - & - \\
\hline & Yes & 1.57 & $0.70,3.52$ & 0.276 \\
\hline \multirow[t]{2}{*}{ Housing Insecure } & No & REF & - & - \\
\hline & Yes & 3.33 & $1.53,7.24$ & 0.002 \\
\hline \multirow[t]{2}{*}{ Affords Medication } & Yes & REF & - & - \\
\hline & No & 1.15 & $0.51,2.61$ & 0.740 \\
\hline \multirow[t]{5}{*}{ Self-reported Health Status } & Excellent & REF & - & - \\
\hline & Very Good & 0.55 & $0.05,5.86$ & 0.622 \\
\hline & Good & 1.29 & $0.14,12.30$ & 0.826 \\
\hline & Fair & 1.25 & $0.12,12.86$ & 0.852 \\
\hline & Poor & 1.22 & $0.11,13.48$ & 0.874 \\
\hline Mobility & No problems & REF & - & - \\
\hline
\end{tabular}


Table 7 Logistic regression of participant characteristics associated with attending the Legal Health Clinic (Continued)

\begin{tabular}{|c|c|c|c|c|}
\hline \multirow[t]{2}{*}{ Variable } & & \multicolumn{3}{|c|}{$\begin{array}{l}\text { Attended the Legal Health Clinic }(n=59) \\
\text { Versus Did not attend }(n=502)\end{array}$} \\
\hline & & OR & $95 \% \mathrm{Cl}$ & $p$-value \\
\hline & Some/Severe problems & 1.56 & $0.65,3.73$ & 0.321 \\
\hline \multirow[t]{2}{*}{ Self-Care } & No problems & REF & - & - \\
\hline & Some/Severe problems & 0.76 & $0.30,1.97$ & 0.575 \\
\hline \multirow[t]{2}{*}{ Usual Activities } & No problems & REF & - & - \\
\hline & Some/Severe problems & 2.83 & $1.08,7.43$ & 0.034 \\
\hline \multirow[t]{2}{*}{ Anxiety/Depression } & No problems & REF & - & - \\
\hline & Some/Severe problems & 0.91 & $0.39,2.13$ & 0.826 \\
\hline \multirow[t]{2}{*}{ Pain/Discomfort } & No problems & REF & - & - \\
\hline & Some/Severe problems & 1.62 & $0.54,4.87$ & 0.392 \\
\hline
\end{tabular}

Note: Bolding denotes risk factors significant at $p<0.05$

though this paper does not measure health outcomes, it is likely that accessing the Legal Clinic will translate into improved health outcomes for these patients [7, 13, 14]. Future research should prospectively follow patients to fully evaluate this impact on health outcomes. Moreover, the implementation of a Legal Clinic will likely benefit clinical practice. Studies that have implemented Legal Clinics have found that clinicians feel as though they are better advocates for their patients by collaborating with a lawyer and knowing where they can refer them [29, 30]. Other family practices may be an ideal setting in which legal services can be provided to vulnerable individuals in a familiar, trusted setting.

\section{Abbreviations}

CPP: Canada Pension Plan; FHT: Family Health Team; HCLC: Hamilton Community Legal Clinic; LAO: Legal Aid Ontario; LHC: Legal Health Clinic; LIM: Low Income Measure; SES: Socioeconomic Status

\section{Acknowledgements}

Not applicable.

\section{Authors' contributions}

$G A, J M$, and DE conceived of the study. GA, DE, BD, HT, and JM initiated the study design and $\mathrm{GA}, \mathrm{DE}, \mathrm{BD}, \mathrm{HT}, \mathrm{JM}$, and $\mathrm{SC}$ contributed to implementation. GA and MP provided epidemiological expertise and MP and BD conducted the statistical analysis. GA and MP drafted the manuscript and all authors contributed to and approved the final manuscript.

\section{Funding}

This work was supported by the Local Poverty Reduction Fund through the Ontario Trillium Foundation (Project No. PR10028). The funding body had no role in the design of the study, data collection, analysis, interpretation of data, or writing the manuscript. HCLC and LAO provided in-kind legal staffing coverage for the Legal Health Clinic during the time period of the study.

\section{Availability of data and materials}

The data are available from the corresponding author upon reasonable request.

\section{Ethics approval and consent to participate}

Ethics approval was provided by the Hamilton Integrated Research Ethics Board (Project \#1085) and all participants provided written consent.

\section{Consent for publication}

Not applicable.

\section{Competing interests}

The authors declare that they have no competing interests.

\section{Author details}

${ }^{1}$ Department of Family Medicine, McMaster University, Hamilton, Canada. ${ }^{2}$ Department of Health Research Methods, Evidence, and Impact, Hamilton, Canada. ${ }^{3}$ McMaster Family Practice, Hamilton Health Sciences, Hamilton, Canada. ${ }^{4}$ Hamilton Community Legal Clinic, Hamilton, Canada. ${ }^{5}$ Legal Aid Ontario, Hamilton, Canada.

Received: 19 March 2020 Accepted: 29 November 2020

Published online: 12 December 2020

\section{References}

1. Ryan AM, Kutob RM, Suther E, Hansen M, Sandel M. Pilot study of impact of medical-legal partnership services on patients' perceived stress and wellbeing. J Health Care Poor Underserved. 2012;23(4):1536-46.

2. Jackson SF, Miller W, Chapman LA, Ford-Jones EL, Ghent E, Pai N. Hospitallegal partnership at Toronto Hospital for Sick Children: the first Canadian experience. Healthc Q. 2012;15(4):55-61.

3. Houseman AW. The future of civil legal aid in the United States; 2005. p. 17.

4. Kaur S, Konkin J, Tepper J, Petch J. Widening the circle of care: adding legal and financial expertise to the health care team [internet]. Healthy Debate. 2014. Available from: https://healthydebate.ca/2014/10/topic/healthpromotion-disease-prevention/widening-circle-care-adding-legal-financialexpertise-health-care-team. [cited 2020 Mar 19].

5. Bloch G, Rozmovits L, Giambrone B. Barriers to primary care responsiveness to poverty as a risk factor for health. BMC Fam Pract. 2011;12:62.

6. Sandel M, Hansen M, Kahn R, Lawton E, Paul E, Parker V, et al. Medical-legal partnerships: transforming primary care by addressing the legal needs of vulnerable populations. Health Aff (Millwood). 2010;29(9):1697-705.

7. Zuckerman B, Sandel M, Lawton E, Morton S. Medical-legal partnerships: transforming health care. Lancet. 2008;372(9650):1615-7.

8. Government of Canada. A backgrounder on poverty in Canada. 2016 Available from: https://www.canada.ca/en/employment-social-development/ programs/poverty-reduction/backgrounder.html. [cited 2020 Mar 19].

9. Zhang X. Low income measurement in Canada: what do different lines and indexes tell us?. 2010. Available from: https://www150.statcan.gc.ca/n1/pub/ 75f0002m/75f0002m2010003-eng.htm. [cited 2020 Mar 19].

10. Rouleau KD. Poverty and policy in Canada. Implications for health and quality of life. Can Fam Physician. 2007 Nov;53(11):1964-5.

11. Wilkinson R, Marmot M, editors. Social determinants of health: the solid facts. 2nd ed. Copenhagen: WHO Regional Office for Europe; 2003. p. 31

12. Roberge $R$, Berthelot JM, Wolfson MG. The health utility index: measuring health differences in Ontario by socioeconomic status. Health Rep. 1995; $7(2): 25-32$. 
13. Mikkonen J, Raphael D. Social determinants of health: the Canadian facts [internet]. Toronto, Ontario: York University School of Health Policy and Management; 2010. Available from: http://books.scholarsportal.info/viewdoc. html?id=/ebooks/ebooks0/gibson_cppc/2010-08-06/6/10390848. [cited 2020 Mar 19].

14. Marmot M, Wilkinson R. Social organization, stress, and health. In: social determinants of health. Second edition. Oxford, New York: Oxford University Press; 2005.

15. Nobleman R. Are health problems legal problems in disguise? Canadian Forum on Civil Justice. 2013; Available from: https://cfcj-fcjc.org/a2jblog/arehealth-problems-legal-problems-in-disguise/. [cited 2020 Mar 19].

16. Sege R, Preer G, Morton SJ, Cabral H, Morakinyo O, Lee V, et al. Medicallegal strategies to improve infant health care: a randomized trial. Pediatrics. 2015;136(1):97-106.

17. Weintraub D, Rodgers MA, Botcheva L, Loeb A, Knight R, Ortega K, et al. Pilot study of medical-legal partnership to address social and legal needs of patients. J Health Care Poor Underserved. 2010;21 (2 Suppl):157-68.

18. Regenstein M, Trott J, Williamson A, Theiss J. Addressing social determinants of health through medical-legal partnerships. Health Aff. 2018;37(3):378-85.

19. Mayo S. Poverty among Hamilton's tax filers [Internet]. Social Planning and Research Council of Hamilton. 2017 [cited 2020 Mar 19]. Available from: http://www.sprc.hamilton.on.ca/wp-content/uploads/2017/04/SPRC-HSLBulletin-14-Poverty-of-taxfilers-April-2017.pdf.

20. Gallimore C, Morasse T, Wingard J. On any given night [internet]. Hamilton; 2007. Available from: http://www.sprc.hamilton.on.ca/wp-content/uploads/2 007/11/COLLAB-On-Any-Given-Night-Measuring-Homelessness-in-HamiltonDecember-2007.pdf. [cited 2020 Mar 19].

21. DeLuca PF, Kanaroglou PS. Code red: explaining average age of death in the City of Hamilton. AlMS Public Health. 2015;2(4):730-45.

22. Statistics Canada. Health Profile: City of Hamilton Health Unit (Health Region), Ontario and Canada (table). Ottawa: Statistics Canada; 2013 Available from: https:/www12.statcan.gc.ca/health-sante/82-228/index.cfm [cited $2020 \mathrm{Mar} 19]$

23. Legal Health Check-Up [Internet]. Halton Legal Clinic. 2014 [cited 2020 Mar 19]. Available from: https://www.legalhealthcheckup.ca/en/.

24. EQ-5D-3L User Guide [Internet]. The Netherlands: EuroQol Research Foundation; 2018 Dec. Available from: https://eurogol.org/docs/EQ-5D-3LUser-Guide.pdf.

25. Statistics Canada. Canadian Community Health Survey (CCHS) - 2019 [Internet]. 2019 [cited 2020 Mar 19]. Available from: https://www23.statcan gc.ca/imdb/p3Instr.pl?Function=assemblelnstr\&lang=en\&ltem_Id=1207185.

26. Brcic V, Eberdt C, Kaczorowski J. Development of a tool to identify poverty in a family practice setting: a pilot study. Int J Family Med. 2011;2011: 812182

27. Kleinman R, Murphy M, Wieneke K, Desmond M, Schiff A, Gapinski J. Use of a single-question screening tool to detect hunger in families attending a neighborhood health center. Ambul Pediatr. 2007 Jul 1;7(4):278-84.

28. Will Legal Aid pay for my lawyer? [Internet]. Legal Aid Ontario. [cited 2020 Mar 19]. Available from: https://www.legalaid.on.ca/will-legal-aid-pay-for-mylawyer/.

29. Roach K, Sossin L. Access to justice and beyond. Univ Toronto Law J. 2010; 60(2):373-95.

30. Paul E, Fullerton DF, Cohen E, Lawton E, Ryan A, Sandel M. Medical-legal partnerships: addressing competency needs through lawyers. J Grad Med Educ. 2009:1(2):304-9.

\section{Publisher's Note}

Springer Nature remains neutral with regard to jurisdictional claims in published maps and institutional affiliations.

Ready to submit your research? Choose BMC and benefit from:

- fast, convenient online submission

- thorough peer review by experienced researchers in your field

- rapid publication on acceptance

- support for research data, including large and complex data types

- gold Open Access which fosters wider collaboration and increased citations

- maximum visibility for your research: over $100 \mathrm{M}$ website views per year

At BMC, research is always in progress.

Learn more biomedcentral.com/submissions 